\title{
Retrospective Real-World Evaluation of Outcomes in Patients with Skin and Soft Structure Infections Treated with Tedizolid in an Outpatient Setting
}

\author{
Ravina Kullar · Laura A. Puzniak · Jason P. Swindle $\cdot$ Thomas Lodise
}

Received: November 25, 2019 / Published online: January 23, 2020

(C) The Author(s) 2020

\begin{abstract}
Introduction: Outcomes data for patients who received tedizolid for acute bacterial skin and skin-structure infections (ABSSSIs) are scant. We provide a real-world analysis of economic and clinical outcomes following tedizolid use in the outpatient setting.

Methods: This retrospective study of adults with skin infections treated with tedizolid (index period: 1 July 2014-31 May 2016) used data from the Optum Research and Impact National Benchmark databases.
\end{abstract}

Enhanced Digital Features To view enhanced digital features for this article go to https://doi.org/10.6084/ m9.figshare.11440911.

Electronic supplementary material The online version of this article (https://doi.org/10.1007/s40121019-00279-0) contains supplementary material, which is available to authorized users.

R. Kullar

Expert Stewardship, Inc., Newport Beach, CA, USA

L. A. Puzniak ( $\varangle)$

Merck \& Co., Inc., Kenilworth, NJ, USA

e-mail: laura.puzniak@merck.com

J. P. Swindle

Optum, Inc., Chicago, IL, USA

T. Lodise

Albany College of Pharmacy and Health Sciences, Albany, NY, USA
Results: Ninety-one patients received tedizolid for the treatment of skin infections (with complications, $n=18$; without complications, $n=73$ ). Some patients had $>1$ complication and infection site. Among patients with complications, pre-index complications during the [index date -30 ] through [index date +1 ] period included osteomyelitis (44.4\%), septicemia (44.4\%), and prosthetic joint/device/graft infection (16.7\%). For the [index date -7 ] through [index date +1 ] period, the infection site included abscesses $(55.6 \%)$ and chronic ulcers $(38.9 \%)$. Mean (standard deviation [SD]) days supplied for the index tedizolid claim was 6.8 (2.3) days. Healthcare resource utilization (HCRU) during the 30-day post-index period included $\geq 1$ ambulatory visit (100.0\%), $\geq 1$ emergency department (ED) visit $(16.7 \%)$, and $\geq 1$ hospitalization (22.2\%). Median 30-day post-index all-cause costs were $\$ 11,098$ [lower quartile $\left(\mathrm{Q}_{1}\right), \quad \$ 5688$; upper quartile $\left(\mathrm{Q}_{3}\right), \quad \$ 16,246$; mean (SD), $\$ 14,637$ $(\$ 11,435)]$. Among patients without complications, the pre-index infection site from ([index date -7 ] through [index date +1 ]) included abscesses (60.3\%), chronic ulcers $(37.0 \%)$, and cellulitis $(2.7 \%)$. Mean (SD) days supplied for the index tedizolid claim was 6.6 (2.5) days. Thirty-day post-index HCRU included $\geq 1$ ambulatory visit (91.8\%), $\geq 1$ ED visit (17.8\%), and $\geq 1$ hospitalization (5.5\%). Median 30-day post-index all-cause costs were $\$ 3230\left(\mathrm{Q}_{1}\right.$, \$2345; $\mathrm{Q}_{3}, \$ 6847 ;$ mean [SD], \$6898 [\$11,129]). 
Conclusions: Patients treated with tedizolid in the outpatient setting experienced a short duration of therapy, low hospital admission, and modest post-index HCRU indicators, suggesting its utility for outpatient therapy of ABSSSIs.

Keywords: Bacterial skin infections; Healthcare resource utilization; Real-world; Tedizolid

\section{Key Summary Points}

\section{Why carry out this study?}

Skin infections are a major source of healthcare resource consumption, and a large portion of the substantial cost is due to hospitalization.

Hospitalization may be unnecessary in certain patients where the sole reason for admission is to receive intravenous antibacterial agents.

We conducted a real-world analysis of economic and clinical outcomes among patients with skin infections treated with tedizolid in the outpatient setting and specifically included patients with complications, as this cohort was excluded from phase 3 trials.

\section{What was learned from this study?}

Among patients treated in the outpatient setting with tedizolid for skin infections, with and without complications, patients had low hospital admission rates and modest post-index healthcare resource utilization indicators after receipt of tedizolid.

Clinical and economic outcomes with tedizolid therapy were consistent with those seen for other outpatient antibiotic therapies.

\section{INTRODUCTION}

In the US healthcare system, management of patients with infections associated with significant mortality, such as pneumonia, or those caused by resistant gram-negative pathogens, is given the highest priority [1]. Infections such as skin and soft tissue infections (SSTIs) are often overlooked and deprioritized. While SSTIs are associated with a lower risk of death relative to other infections, SSTIs are a major source of morbidity and healthcare resource consumption in both the community and hospital settings [2-4]. Hospital admissions to treat patients with SSTIs comprised $1.8 \%$ of all hospitalizations between 2005 and 2011 and have continued to increase [2]. Costs associated with hospitalization are substantial, with the mean cost for an SSTI inpatient episode ranging from $\$ 8865$ to $\$ 40,046[5,6]$. Management of patients with SSTIs has been further complicated by shifts in causal pathogens and antibiotic susceptibilities. Once a disease state that was largely attributed to Streptococcus pyogenes, Staphylococcus aureus [including methicillin-resistant $S$. aureus (MRSA)] is now the predominant cause of SSTIs; the incidence of $S$. aureusrelated SSTI hospitalizations in the US significantly increased from 2001 to 2009 (57 to 117 cases/100,000 people; $p<0.01$ ) [6].

In an era of healthcare reform, healthcare systems are mandated to deliver high-quality care at the lowest cost [7]. For patients with skin infections, avoiding hospital admission or shortening the length of hospital stay for appropriate patients can minimize cost $[8,9]$. Patients with skin infections may be admitted solely to receive intravenous (IV) antibacterial agents despite having few, if any, comorbid conditions or any systemic signs/symptoms of infection $[9,10]$. Furthermore, patients often remain hospitalized even after their acute infection resolves, and it is possible to discharge these patients with continued oral antibiotic therapy without compromising their outcomes $[10,11]$. A survey of 94 patients with skin infections across six US hospital emergency departments (EDs) revealed that $40 \%$ of patients preferred to be treated at home [12]. 
In response to the emergence of skin infections due to MRSA, several new antibiotics have been developed and approved [13]. Sivextro ${ }^{\circledR}$ (tedizolid phosphate; henceforth, tedizolid) is an oxazolidinone-class antibacterial drug, indicated to treat adults with acute bacterial skin and skin-structure infection (ABSSSI) caused by susceptible isolates of gram-positive bacteria, including MRSA [14]. Tedizolid has once-a-day dosing and a shorter duration of therapy compared with linezolid (6 vs. 10-14 days) [14]. Also, tedizolid may be better tolerated (i.e., gastrointestinal effects) and have fewer drug interactions than linezolid [14-17]. With bioequivalent IV and oral formulations and favorable safety, appropriate patients may be considered for outpatient treatment with tedizolid, thereby reducing hospitalization length of stay or avoiding hospitalization entirely $[8,9,17]$. Use of an oral agent such as tedizolid offers an appropriate early switch option from IV therapy following clinical improvement, which can result in reduced IV antibiotic use and attributed risks, savings in drug acquisition costs, and decreased required nursing time, without resulting in increased readmission rates $[18,19]$.

Beyond its pivotal phase 3 clinical trials, outcomes data for patients who received tedizolid for ABSSSI are scant [14, 15, 17]. To date, there has not been a real-world analysis of the economic and clinical effect of tedizolid in the outpatient setting. The aim of this study was to describe economic outcomes among patients with skin infections treated with tedizolid in the outpatient setting, including the ED and ambulatory settings.

\section{METHODS}

\section{Ethics Compliance}

No patient's identity or medical records were disclosed for the purposes of this study except in compliance with applicable law. As the information obtained was deidentified in such a manner that the identity of the human subjects cannot be readily ascertained directly or through identifiers linked to the subjects, this study did not meet the requirements for institutional review board (IRB) review as per the US Department of Health and Human Services title 45 Code of Federal Regulations part 46 subpart A.

\section{Study Design and Sample}

This was a retrospective study of adult ( $\geq 18$ years of age) commercial or Medicare Advantage enrollees from the Optum Research Database and the Impact National Benchmark Database and linked race/ethnicity information and mortality data from 1 April 2014 through 30 June 2016 (Fig. 1). The index date was defined as the first medical or pharmacy claim for tedizolid during the identification period (1 July 2014-31 May 2016). Only patients with index dates that did not overlap a hospitalization were included in this analysis. The ED/ ambulatory group included patients with an index claim: (1) on the same day as an ED visit, (2) on the same day as an ambulatory (including office and outpatient) visit, or (3) not on the same day as an encounter (i.e., inpatient stay, $\mathrm{ED}$ visit, or ambulatory visit). For patients in the ED/ambulatory group, the date of the index claim was defined as the index date. Patients were required to have continuous enrollment in the health plan (with both medical and pharmacy coverage) during the 91 days before (and excluding) the index date and for a minimum of 30 days after (and including) the index date until the earliest of 30 June 2016, disenrollment, death, or 91 days following the index date. To identify prior skin infection, it was required that patients had a medical claim with a diagnosis code for a skin infection during the period of [index date -7] through [index date +1$]$, without a non-skin infection occurring closer to the index date. Similar to Mullins et al. [20], this study relied on complicated skin and skin-structure infection (cSSSI; Supplementary Table S1) rather than ABSSSI codes, given the lack of clinical data in administrative claims that are relevant to diagnosing ABSSSI.

Patients were stratified by whether or not they had a complication. A complication was defined as a diagnosis code for bacteremia, 


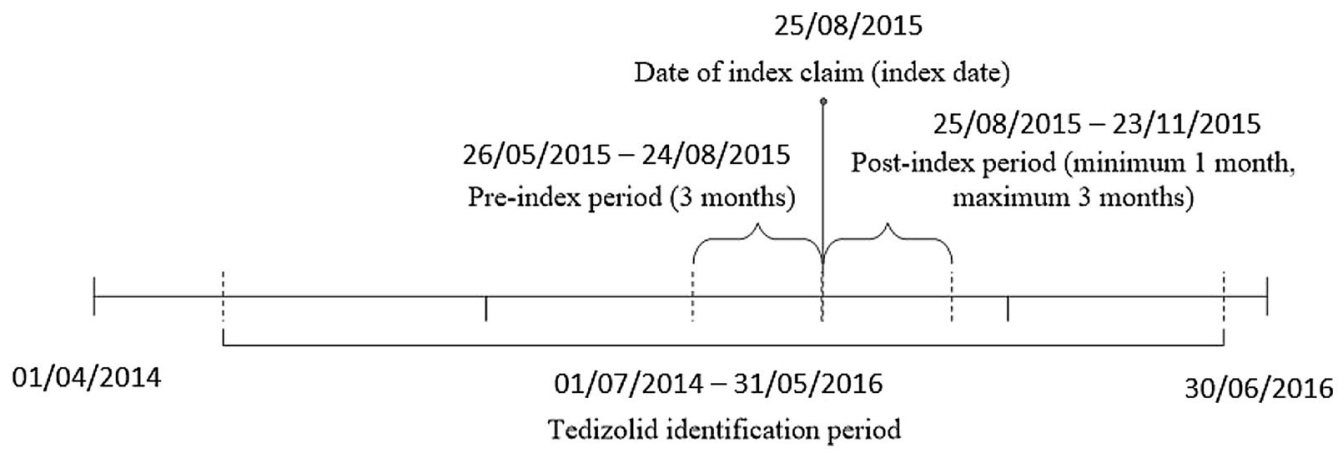

Fig. 1 Patient identification timeline

endocarditis, gangrene, meningitis, necrotizing fasciitis, osteomyelitis, prosthetic joint/device/graft infection, or septicemia during the period of [index date - 30] through [index date +1 ] (Supplementary Table S1).

\section{Patient Data}

Patient characteristics recorded at the index date included age, sex, race/ethnicity, health plan type, and geographic region. The pre-index Quan-Charlson comorbidity score was calculated [7, 21]. Pre-index comorbid conditions were captured using the Clinical Classifications Software (CCS) managed by the Agency for Healthcare Research and Quality. Type of skin infection was assessed during the period of [index date -7 ] through [index date +1 ]. When $\geq 2$ infections were recorded on the same date, infection type was assigned according to infection severity: (1) chronic ulcer, (2) postoperative infection, (3) wound infection, (4) abscess, (5) cellulitis, and (6) furuncle. Complications were calculated during the period of [index date -30 ] through [index date +1 ]. Antibiotic fills were calculated for the period of [index date - 30] through [index date - 1]. The following variables were recorded for the index tedizolid claim: dose, route of administration, prescriber specialty [internal medicine, family/general practice, surgery (all types), other, and unknown], and days supplied.

All-cause healthcare resource utilization (HCRU; hospitalizations, ambulatory visits, and ED visits) and healthcare costs (total, medical, hospital, ambulatory, emergency services, and pharmacy) were calculated for the period of [index date - 30] through [index date - 1]. Costs expressed in US dollars (\$) were adjusted to 2016 costs using the annual medical care component of the Consumer Pricing Index (CPI) to reflect inflation between 2014 and 2016.

\section{Outcomes}

The count of subsequent claims for tedizolid during a maximum of 91 days post-index was calculated, and total days supplied was categorized as $1-6,7-12$, and $\geq 13$ days. The following burden of illness outcomes were evaluated for the period of the index date through [index date + 29]: (1) HCRU (all cause and skin infection related; hospitalizations, ambulatory visits, and ED visits), (2) CPI-adjusted healthcare costs (all-cause; total, medical, hospital, ambulatory, emergency services, and pharmacy), and (3) antibiotic therapy related to skin infection (encompassing any agent indicated primarily against gram-positive bacteria).

\section{Statistical Methods}

All study variables, including outcomes and covariates of interest, were descriptively evaluated for patients with skin infections, stratified by complication status. Numbers and percentages were reported for dichotomous and polychotomous variables. Means, standard deviations (SDs), and medians were reported for continuous variables [additionally, lower 
quartile $\left(\mathrm{Q}_{1}\right)$ and upper quartile $\left(\mathrm{Q}_{3}\right)$ values for HCRU/costs]. All-cause hospital costs, ambulatory costs, and emergency services costs (preand post-index) were reported for users (e.g., ambulatory costs for patients with $\geq 1$ ambulatory visit). Missing data were reported as a category where appropriate.

\section{RESULTS}

\section{Demographics and Clinical Characteristics}

Of 91 patients with skin infections receiving tedizolid, 18 had complications and 73 had no complications. Patient demographics and clinical characteristics are provided in Table 1.

\section{Patients with Skin Infections with Complications}

Of 18 patients with skin infections with complications who received tedizolid in an outpatient setting, the mean (SD) age was 54.2 (15.1) years, and $66.7 \%$ were female. Patients were predominantly from the South $(50.0 \%)$, followed by the West $(27.8 \%)$ and Midwest (16.7\%). A pre-index Quan-Charlson comorbidity score of $1-2$ existed in $50.0 \%$ of patients. Common pre-index CCS comorbidities were skin and subcutaneous tissue infections $(88.9 \%)$, other connective tissue diseases (83.3\%), hypertension $(77.8 \%)$, and bacterial infections (72.2\%). Some patients had $>1$ complication and infection site. Pre-index complications during the period of [index date -30 ] through [index date +1 ] included osteomyelitis $(44.4 \%)$, septicemia $(44.4 \%)$, and prosthetic joint/device/graft infection (16.7\%). The pre-index infection site closest to the index date during the period of [index date -7] through [index date +1 ] included abscesses (55.6\%) and chronic ulcers (38.9\%).

Pre-index all-cause HCRU during the period of [index date -30 ] through [index date -1] included $\geq 1 \quad$ hospitalization $\quad(44.4 \%$; $n=8), \geq 1$ ambulatory visit $(94.4 \% ; n=17)$, and $\geq 1$ ED visit (38.9\%; $n=7$; Fig. 2). Onethird $(33.3 \% ; n=6)$ of patients were discharged
Table 1 Demographics and clinical characteristics

\begin{tabular}{|c|c|c|}
\hline & $\begin{array}{l}\text { Skin infections } \\
\text { with } \\
\text { complications } \\
(n=18)\end{array}$ & $\begin{array}{l}\text { Skin infections } \\
\text { without } \\
\text { complications } \\
(n=73)\end{array}$ \\
\hline \multicolumn{3}{|l|}{ Age, years } \\
\hline Mean (SD) & $54.2(15.1)$ & $58.5(15.7)$ \\
\hline Median & 50.5 & 61.0 \\
\hline \multicolumn{3}{|l|}{ Sex, $n(\%)$} \\
\hline Female & $12(66.7)$ & $34(46.6)$ \\
\hline \multicolumn{3}{|c|}{ Race/ethnicity, $n$ (\%) } \\
\hline White & $15(83.3)$ & $47(64.4)$ \\
\hline African American & $0(0.0)$ & $2(2.7)$ \\
\hline Hispanic & $2(11.1)$ & $8(11.0)$ \\
\hline Asian & $0(0.0)$ & $1(1.4)$ \\
\hline Other & $0(0.0)$ & $1(1.4)$ \\
\hline Missing & $1(5.6)$ & $14(19.2)$ \\
\hline \multicolumn{3}{|c|}{ Health plan type, $n(\%)$} \\
\hline Commercial & $13(72.2)$ & $43(58.9)$ \\
\hline $\begin{array}{l}\text { Medicare } \\
\text { advantage }\end{array}$ & $5(27.8)$ & $30(41.1)$ \\
\hline \multicolumn{3}{|c|}{ Geographic region, $n(\%)$} \\
\hline Northeast & $1(5.6)$ & $11(15.1)$ \\
\hline Midwest & $3(16.7)$ & $9(12.3)$ \\
\hline South & $9(50.0)$ & $46(63.0)$ \\
\hline West & $5(27.8)$ & $6(8.2)$ \\
\hline Unknown & $0(0.0)$ & $1(1.4)$ \\
\hline \multicolumn{3}{|c|}{ 91-day pre-index Quan-Charlson comorbidity score, $n$ (\%) } \\
\hline 0 & $5(27.8)$ & $41(56.2)$ \\
\hline $1-2$ & $9(50.0)$ & $13(17.8)$ \\
\hline $3-4$ & $4(22.2)$ & $14(19.2)$ \\
\hline$\geq 5$ & $0(0.0)$ & $5(6.9)$ \\
\hline \multicolumn{3}{|c|}{$\begin{array}{l}\text { 91-day pre-index Quan-Charlson comorbid conditions, } \\
n(\%)\end{array}$} \\
\hline
\end{tabular}


Table 1 continued

\begin{tabular}{|c|c|c|}
\hline & $\begin{array}{l}\text { Skin infections } \\
\text { with } \\
\text { complications } \\
(n=18)\end{array}$ & $\begin{array}{l}\text { Skin infections } \\
\text { without } \\
\text { complications } \\
(n=73)\end{array}$ \\
\hline $\begin{array}{l}\text { Chronic } \\
\text { pulmonary } \\
\text { disease }\end{array}$ & $4(22.2)$ & $9(12.3)$ \\
\hline $\begin{array}{l}\text { Diabetes with } \\
\text { chronic } \\
\text { complication }\end{array}$ & $7(38.9)$ & $14(19.2)$ \\
\hline Renal disease & $3(16.7)$ & $11(15.1)$ \\
\hline $\begin{array}{l}\text { Rheumatologic } \\
\text { disease }\end{array}$ & $3(16.7)$ & $4(5.5)$ \\
\hline $\begin{array}{l}\text { Any malignancy, } \\
\text { including } \\
\text { leukemia and } \\
\text { lymphoma }\end{array}$ & $1(5.6)$ & $3(4.1)$ \\
\hline Dementia & $0(0.0)$ & $1(1.4)$ \\
\hline Heart failure & $4(22.2)$ & $12(16.4)$ \\
\hline $\begin{array}{l}\text { Hemiplegia or } \\
\text { paraplegia }\end{array}$ & $0(0.0)$ & $0(0.0)$ \\
\hline Mild liver disease & $1(5.6)$ & $6(8.2)$ \\
\hline AIDS/HIV & $0(0.0)$ & $1(1.4)$ \\
\hline $\begin{array}{l}\text { Moderate or } \\
\text { severe liver } \\
\text { disease }\end{array}$ & $0(0.0)$ & $0(0.0)$ \\
\hline $\begin{array}{l}\text { Metastatic solid } \\
\text { tumor }\end{array}$ & $0(0.0)$ & $1(1.4)$ \\
\hline
\end{tabular}

AIDS acquired immunodeficiency syndrome, $H I V$ human immunodeficiency virus, $S D$ standard deviation

(all-cause) in the 7 days before the index date. The median all-cause total costs during the period of [index date -30 ] through [index date - 1] were $\$ 14,001\left(Q_{1} \$ 7154 ; Q_{3} \$ 33,179\right.$; mean [SD], $\$ 19,185$ [\$15,595]). Median medical and pharmacy costs were $\$ 13,531\left(\mathrm{Q}_{1}, \$ 4658\right.$;
$\left.\mathrm{Q}_{3}, \$ 30,696\right)$ and $\$ 483\left(\mathrm{Q}_{1}, \$ 157 ; \mathrm{Q}_{3}, \$ 1104\right)$, respectively. Median hospital costs for users comprised \$11,655 $\left(\mathrm{Q}_{1}, \$ 8031 ; \mathrm{Q}_{3}, \$ 23,944\right)$. Median ambulatory and emergency services costs for users were $\$ 3506\left(\mathrm{Q}_{1}, \$ 1493 ; \mathrm{Q}_{3}\right.$, $\$ 8427)$ and $\$ 423\left(\mathrm{Q}_{1}, \quad \$ 113 ; \mathrm{Q}_{3}, \quad \$ 475\right)$, respectively.

All patients received tedizolid $200 \mathrm{mg}$ orally at index; an internal medicine physician originated $66.7 \%$ of these prescriptions. The mean (SD) days supplied for the index tedizolid claim was 6.8 (2.3) days. Total outpatient days supplied for combined tedizolid fills for the index date through [index date +90 ] included 1-6 days $\quad(72.2 \%), \quad 7-12$ days (11.1\%), and $\geq 13$ days (16.7\%). Approximately half of patients $(55.6 \%)$ had evidence of treatment with an anti-gram-positive agent other than tedizolid following the index date (i.e., index date through [index date +29 ]), whereas $66.7 \%$ were treated with an anti-gram-positive agent during the period of [index date - 30] through [index date - 1].

During the first month following the index date among patients with skin infections with complications, $22.2 \%(n=4)$ had $\geq 1$ all-cause hospitalization [skin infection-related, 16.7\% $(n=3)], \quad 100.0 \% \quad(n=18) \quad$ had $\geq 1 \quad$ all-cause ambulatory visit [skin infection-related, $77.8 \%$ $(n=14)]$, and $16.7 \%(n=3)$ had $\geq 1$ all-cause ED visit [skin infection-related, $0.0 \%(n=0)$; Fig. 2]. Median all-cause costs included total costs $\$ 11,098\left(\mathrm{Q}_{1} \$ 5688 ; \mathrm{Q}_{3} \$ 16,246 ;\right.$ mean [SD], $\$ 14,637$ [\$11,435]), medical costs $\$ 7983$ $\left(\mathrm{Q}_{1} \$ 2472 ; \mathrm{Q}_{3}\right.$ \$14,049), and pharmacy costs \$2126 ( $\mathrm{Q}_{1}$ \$1927; $\mathrm{Q}_{3}$ \$2971). Median hospital costs for users comprised $\$ 3314\left(\mathrm{Q}_{1} \$ 919 ; \mathrm{Q}_{3}\right.$ $\$ 5399$ ). Median ambulatory and emergency services costs for users were $\$ 2916\left(\mathrm{Q}_{1} \$ 1315\right.$; $\left.\mathrm{Q}_{3} \$ 12,541\right)$ and $\$ 274\left(\mathrm{Q}_{1} \$ 238 ; \mathrm{Q}_{3} \$ 525\right)$, respectively.

\section{Patients with Skin Infections Without Complications}

Of 73 patients with skin infections without complications who received tedizolid, the mean (SD) age was 58.5 (15.7) years and $46.6 \%$ were female. Patients were predominantly from the 


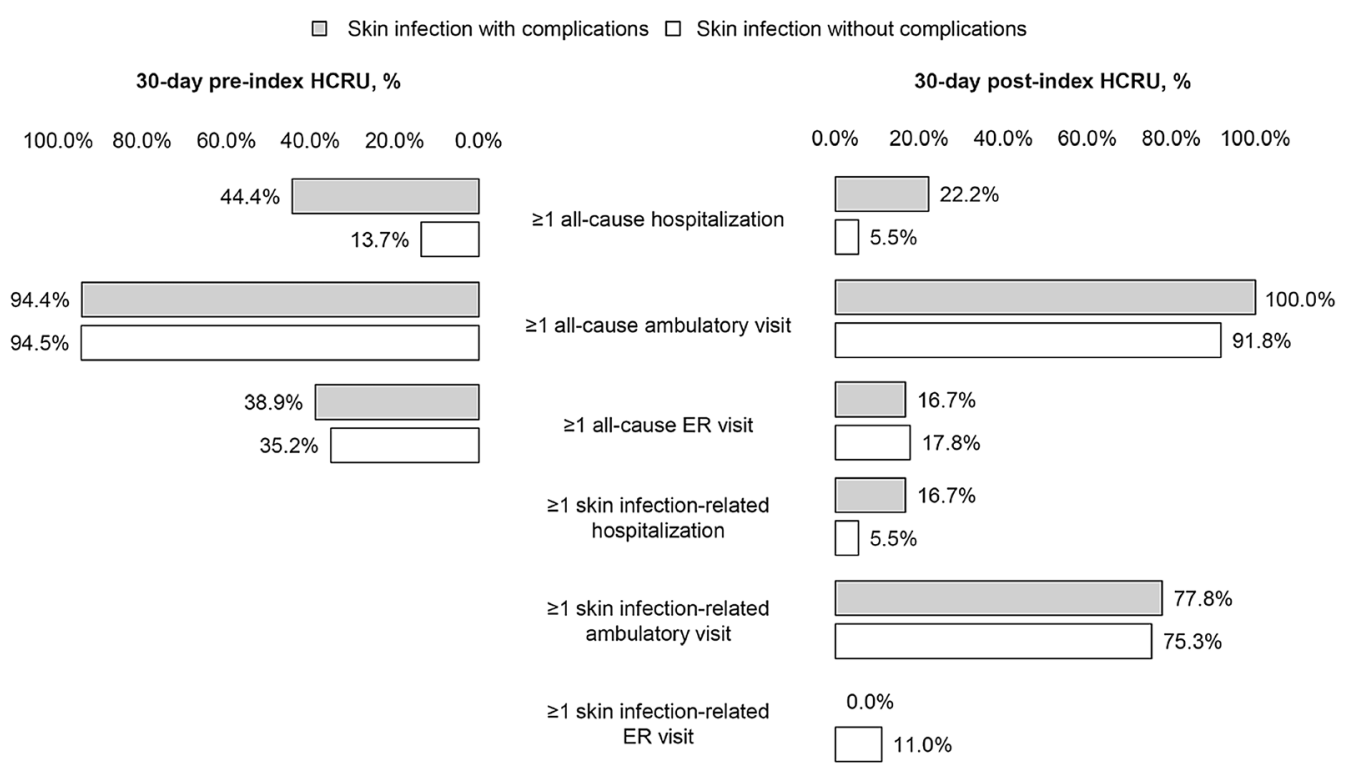

Fig. 2 30-day pre- and post-index tedizolid claim healthcare resource utilization among patients with skin infections, with and without complications

South (63.0\%), followed by the Northeast (15.1\%) and Midwest (12.3\%). More than half $(56.2 \%)$ of patients had a pre-index QuanCharlson comorbidity score of 0 . Common preindex CCS comorbidities were skin and subcutaneous tissue infections $(75.3 \%)$, other connective tissue diseases (54.8\%), hypertension $(45.2 \%)$, and diseases of veins and lymphatics (45.2\%). The pre-index infection site closest to the index date during the period of [index date -7 ] through [index date +1 ] included abscesses (60.3\%), chronic ulcers $(37.0 \%)$, and cellulitis $(2.7 \%)$.

Pre-index all-cause HCRU during the period of [index date -30 ] through [index date -1] included $\geq 1 \quad$ hospitalization $\quad(13.7 \%$; $n=10)$, $\geq 1$ ambulatory visit $(94.5 \% ; n=69)$, and $\geq 1$ ED visit (35.2\%; $n=25$; Fig. 2 ). Less than one in ten $(8.2 \% ; n=6)$ patients were discharged (all cause) in the 7 days before the index date. Patients with skin infections without complications had median all-cause total costs during the [index date - 30] through [index date -1$]$ period of $\$ 3843\left(\mathrm{Q}_{1} \$ 969 ; \mathrm{Q}_{3}\right.$ \$7922; mean [SD], \$6442 [\$11,240]). Median medical and pharmacy costs were $\$ 2967\left(\mathrm{Q}_{1}\right.$ $\left.\$ 595 ; \mathrm{Q}_{3} \$ 6708\right)$ and $\$ 170\left(\mathrm{Q}_{1} \$ 28 ; \mathrm{Q}_{3} \$ 616\right)$, respectively. Median inpatient costs for users comprised \$7158 ( $\mathrm{Q}_{1} \$ 6070 ; \mathrm{Q}_{3}$ \$7585). Median ambulatory and emergency services costs for users were $\$ 1066\left(\mathrm{Q}_{1} \$ 320 ; \mathrm{Q}_{3} \$ 2887\right)$ and $\$ 437$ $\left(\mathrm{Q}_{1} \$ 292 ; \mathrm{Q}_{3} \$ 732\right)$, respectively.

All patients received tedizolid $200 \mathrm{mg}$ orally, with $52.1 \%$ and $11.0 \%$ of patients prescribed the drug by an internal medicine physician and surgeon, respectively. The mean (SD) days supplied for the index tedizolid claim was $6.6(2.5)$ days. Total outpatient days supplied for the index date through [index date +90 ] tedizolid claims was $1-6$ days (75.3\%), $7-12$ days (15.1\%), and $\geq 13$ days $(9.6 \%)$. Evidence of treatment with an anti-gram-positive agent other than tedizolid following the index date (i.e., index date through [index date +29 ]) was observed for $31.5 \%$ of patients, whereas $58.9 \%$ were treated with an anti-gram-positive agent during the period of [index date - 30] through [index date - 1] ( $\beta$-lactam, 27.4\%; trimethoprim-sulfamethoxazole, $26.0 \%$ ).

During the first month following the index date among patients with skin infections without complications, 5.5\% $(n=4)$ had $\geq 1$ allcause hospitalization [skin infection-related, $5.5 \%(n=4)$ ], $91.8 \%(n=67)$ had $\geq 1$ all-cause ambulatory visit [skin infection-related, 75.3\% $(n=55)]$, and $17.8 \%(n=13)$ had $\geq 1$ all-cause 
ED visit [skin infection-related, $11.0 \%(n=8)$ ]. Median all-cause costs included total costs $\$ 3230\left(\mathrm{Q}_{1} \$ 2345 ; \mathrm{Q}_{3}\right.$ \$6847; mean [SD], \$6898 $[\$ 11,129])$, medical costs $\$ 646\left(\mathrm{Q}_{1} \$ 257 ; \mathrm{Q}_{3}\right.$ $\$ 3764)$, and pharmacy costs $\$ 2031\left(\mathrm{Q}_{1} \$ 1846\right.$; $\mathrm{Q}_{3}$ \$3126). Median hospital costs for users comprised \$10,836 ( $\left.\mathrm{Q}_{1} \$ 10,431 ; \mathrm{Q}_{3} \$ 16,312\right)$. Median ambulatory and emergency services costs for users were $\$ 575\left(\mathrm{Q}_{1} \$ 226 ; \mathrm{Q}_{3} \$ 2124\right)$ and $\$ 641\left(\mathrm{Q}_{1} \$ 278 ; \mathrm{Q}_{3} \$ 712\right)$, respectively.

\section{DISCUSSION}

We analyzed the economic and clinical outcomes of patients with skin infections treated with tedizolid in the outpatient setting, including patients with and without complications $[14,15]$. Overall, the outcomes data were largely favorable with outpatient use of tedizolid for patients with SSTIs. Although there was no comparator group, hospital admissions-one of the most important healthcare quality metrics-was found to be highly acceptable, especially in the group with no complications at index; $5.5 \%$ and $16.7 \%$ of patients with non-complicated and complicated SSTIs had a 30-day skin-related hospital admission, respectively. Thirty-day healthcare costs associated with tedizolid for patients without complications were relatively modest, at a median cost of $\$ 3230$. Patients with complications treated with tedizolid had deepseated and chronic infections, including osteomyelitis, septicemia, prosthetic joint infections, and gangrene. Accordingly, median costs were higher in this cohort $(\$ 11,098)$. Total outpatient days supplied for combined tedizolid fills during the index date through [index date +90 ] most commonly ranged from 1 to 6 days.

Phase 3 clinical trial results showed that tedizolid $200 \mathrm{mg}$ every day for 6 days is noninferior to linezolid $600 \mathrm{mg}$ every $12 \mathrm{~h}$ for 10 days $[14,15]$. Tedizolid was well tolerated, and $<1 \%$ of patients discontinued therapy because of a treatment-emergent adverse event. Based on the two phase 3 trials (ESTABLISH-1 and ESTABLISH-2), a post hoc analysis of tedizolid versus linezolid in an outpatient setting found similar efficacy rates; however, more tedizolid-treated patients $(89.3 \%)$ than linezolid-treated patients $(77.3 \%)$ were compliant with treatment, suggesting a benefit of shortcourse antibiotics in the outpatient setting [22]. While these data support use of tedizolid in the outpatient setting, clinicians need evidence beyond what is provided in clinical trials to determine the value of new agents, particularly in populations frequently excluded from trials. A recent case series of four patients with cSSSIs successfully treated with tedizolid was described [23]. Two patients were morbidly obese with non-necrotizing, non-purulent severe cellulitis, complicated by sepsis or systemic inflammatory response syndrome plus myositis. The other two patients had complicated surgical site infections that failed a long course of IV antibiotics. All four patients responded to tedizolid therapy within $48-72 \mathrm{~h}$ with cessation of lesion spread, detectable reduction in erythema, lack of fever, reduction in pain, and/or improvement of laboratory parameters.

The 30-day healthcare costs associated with tedizolid for patients with skin infections without complications in this study were similar to other reports. Mullins et al. used administrative claims databases to compare rehospitalization rates and total direct medical costs among patients with cSSSI treated with linezolid or vancomycin after hospital discharge [20]. Mean 30-day costs associated with patients treated with vancomycin and linezolid for skin infections were $\$ 7964$ and $\$ 5256$, respectively. A separate administrative claims database study by McKinnon and colleagues revealed similar findings in a cSSSI subgroup, where mean healthcare costs were $\$ 9244$ and $\$ 7794$ for patients on vancomycin and linezolid, respectively [24].

For both complicated (skin infection-related, $16.7 \%$ ) and uncomplicated (skin infectionrelated, 5.5\%) SSSIs, hospital admissions after tedizolid treatment in the outpatient setting were similar to or lower than nationally reported 30-day readmission rates (20\%) [25]. Patients treated with vancomycin (13\%) and linezolid (7\%) in the Mullins et al. study had similar 30-day rehospitalization rates as our cSSSI cohort. Hospitalization results in 
substantial costs; Lodise et al. found that median inpatient costs were $\$ 4385$ in hospitalized patients with skin infections, a Charlson comorbidity index score of 0 , and limited to no systemic signs and symptoms of infection [9].

This study revealed that patients treated with tedizolid in the outpatient setting experienced a short duration of therapy, low hospital admissions, and modest post-index HCRU indicators. This is the first real-world analysis of the economic and clinical impact of tedizolid in the outpatient setting.

When interpreting this retrospective observational study, there are several limitations. It is important to note that due to the nature of the study, causality cannot be inferred. Given the retrospective nature of this study and utilization of a claims database, not all clinical and therapeutic information, such as lesion surface area and causative microorganisms, was available, which may have impacted outcomes. Furthermore, there was no comparator group, limiting both internal and external validity. This study was also performed in the US, with the pharmacoeconomic aspects likely not applicable to other countries where costs differ. In addition, the data source used in this study was a claims database intended to facilitate payment and not research. Use of International Classification of Diseases, 9th and 10th Revision, Clinical Modification diagnosis codes for cSSSI may also be considered a limitation because the codes assigned to the patient only reflect the claims that physicians/facilities submit for reimbursement for that visit and may not align with a confirmed diagnosis, in that patients may be initially miscoded or misdiagnosed. Similarly, pharmacy claims data cannot ensure the patient used the medication as prescribed: these data only document that a claim was submitted. The value of claims data lies in the efficient and effective examination of healthcare outcomes, treatment patterns, HCRU, and costs in a "realworld" setting that includes a large number of patients with varied medical histories. Finally, this study was focused on tedizolid, and other therapeutic options (including surgery) were not part of the study design. Such details should be of interest for future analyses.

\section{CONCLUSIONS}

Among patients with skin infections, with and without complications, treated in the outpatient setting with tedizolid, hospital admissions were low, and all-cause and skin infection-related HCRU in the 30 days after receipt of tedizolid were modest and consistent with other outpatient antibiotic therapies. While comparative studies are warranted, these findings support the use of tedizolid in an outpatient setting for treatment of ABSSSIs.

\section{ACKNOWLEDGEMENTS}

Funding. Funding for this study and the journal's Rapid Service Fees were provided by Merck Sharp \& Dohme Corp, a subsidiary of Merck \& Co., Inc., Kenilworth, NJ, USA (MSD).

Medical Writing/Editorial Assistance. Medical writing and/or editorial assistance was provided by Alanna Kennedy, PhD, CMPP, of The Lockwood Group, Stamford, CT, USA. Funding for this assistance was provided by MSD.

Authorship. All named authors meet the International Committee of Medical Journal Editors (ICMJE) criteria for authorship for this article, take responsibility for the integrity of the work as a whole, and have given their approval for this version to be published. All authors are responsible for the work described in this paper. All authors were involved in at least one of the following: (conception, design of work or acquisition, analysis, interpretation of data) and (drafting the manuscript and/or revising/reviewing the manuscript for important intellectual content). All authors provided final approval of the version to be published. All authors agree to be accountable for all aspects of the work in ensuring that questions related to the accuracy or integrity of any part of the work are appropriately investigated and resolved.

Disclosures. Ravina Kullar and Jason P. Swindle have no conflicts of interest. Thomas 
Lodise consults for MSD. Laura A. Puzniak is an employee of MSD, who may own stock and/or hold stock options in the Company.

Compliance with Ethics Guidelines. No patient's identity or medical records were disclosed for the purposes of this study except in compliance with applicable law. This study did not meet the requirements for institutional review board (IRB) review: human subjects research that is conducted or supported by a Federal department or agency that has adopted the "Common Rule" (US Department of Health and Human Services title 45 Code of Federal Regulations part 46 subpart A) and that does not meet the criteria for exemption or is regulated by the US FDA is subject to review and approval by an IRB. Patient consent for publication was not required.

Data Availability. The data analyzed are owned by Optum and cannot be made available to other researchers for purposes of replicating analysis procedures or reproducing study results.

Open Access. This article is licensed under a Creative Commons Attribution 4.0 International License, which permits use, sharing, adaptation, distribution and reproduction in any medium or format, as long as you give appropriate credit to the original author(s) and the source, provide a link to the Creative Commons licence, and indicate if changes were made. The images or other third party material in this article are included in the article's Creative Commons licence, unless indicated otherwise in a credit line to the material. If material is not included in the article's Creative Commons licence and your intended use is not permitted by statutory regulation or exceeds the permitted use, you will need to obtain permission directly from the copyright holder. To view a copy of this licence, visit http:// creativecommons.org/licenses/by/4.0/.

\section{REFERENCES}

1. The White House. National action plan for combating antibiotic-resistant bacteria. 2015. https:// www.cdc.gov/drugresistance/pdf/national_action_ plan_for_combating_antibotic-resistant_bacteria. pdf. Accessed 12 Aug 2019.

2. Kaye KS, Patel DA, Stephens JM, Khachatryan A, Patel A, Johnson K. Rising United States hospital admissions for acute bacterial skin and skin structure infections: recent trends and economic impact. PLoS One. 2015;10(11):e0143276.

3. Keyloun KR, Weber DJ, Gardstein BM, Berger A, Gillard P, Ganz ML. Economic burden of hospital admissions for patients with acute bacterial skin and skin structure infections in the United States. Hosp Pract. 2018;46(5):278-86.

4. Lee BY, Singh A, David MZ, et al. The economic burden of community-associated methicillin-resistant Staphylococcus aureus (CA-MRSA). Clin Microbiol Infect. 2013;19(6):528-36.

5. Miller LG, Eisenberg DF, Liu H, et al. Incidence of skin and soft tissue infections in ambulatory and inpatient settings, 2005-2010. BMC Infect Dis. $2015 ; 15: 362$.

6. Suaya JA, Mera RM, Cassidy A, et al. Incidence and cost of hospitalizations associated with Staphylococcus aureus skin and soft tissue infections in the United States from 2001 through 2009. BMC Infect Dis. 2014;14:296.

7. Quan H, Sundararajan V, Halfon P, et al. Coding algorithms for defining comorbidities in ICD-9-CM and ICD-10 administrative data. Med Care. 2005;43(11):1130-9.

8. Gray A, Dryden M, Charos A. Antibiotic management and early discharge from hospital: an economic analysis. J Antimicrob Chemother. 2012;67(9):2297-302.

9. Lodise TP, Fan W, Sulham KA. Hospital admission patterns in adult patients with skin and soft tissue infections: identification of potentially avoidable hospital admissions through a retrospective database analysis. Hosp Pract. 2015;43(3):137-43.

10. Talan DA, Salhi BA, Moran GJ, et al. Factors associated with decision to hospitalize emergency department patients with skin and soft tissue infection. West J Emerg Med. 2015;16(1):89-97.

11. Nathwani D, Dryden M, Garau J. Early clinical assessment of response to treatment of skin and soft-tissue infections: how can it help clinicians? Perspectives from Europe. Int J Antimicrob Agents. 2016;48(2):127-36.

12. Almarzoky Abuhussain SS, Burak MA, Kohman KN, et al. Patient preferences for treatment of acute bacterial skin and skin structure infections in the 
emergency department. BMC Health Serv Res. 2018;18(1):932.

13. Abbas M, Paul M, Huttner A. New and improved? A review of novel antibiotics for gram-positive bacteria. Clin Microbiol Infect. 2017;23(10):697-703.

14. Moran GJ, Fang E, Corey GR, Das AF, De Anda C, Prokocimer P. Tedizolid for 6 days versus linezolid for 10 days for acute bacterial skin and skin-structure infections (ESTABLISH-2): a randomised, double-blind, phase 3, non-inferiority trial. Lancet Infect Dis. 2014;14(8):696-705.

15. Flanagan S, Bartizal K, Minassian SL, Fang E, Prokocimer P. In vitro, in vivo, and clinical studies of tedizolid to assess the potential for peripheral or central monoamine oxidase interactions. Antimicrob Agents Chemother. 2013;57(7):3060-6.

16. Prokocimer P, De Anda C, Fang E, Mehra P, Das A. Tedizolid phosphate vs linezolid for treatment of acute bacterial skin and skin structure infections: the ESTABLISH-1 randomized trial. JAMA. 2013; 309(6):559-69.

17. Shorr AF, Lodise TP, Corey GR, et al. Analysis of the phase 3 ESTABLISH trials of tedizolid versus linezolid in acute bacterial skin and skin structure infections. Antimicrob Agents Chemother. 2015;59(2):864-71.

18. Seaton RA, Bell E, Gourlay Y, Semple L. Nurse-led management of uncomplicated cellulitis in the community: evaluation of a protocol incorporating intravenous ceftriaxone. J Antimicrob Chemother. 2005;55(5):764-7.
19. Marks M, Bell LCK, Jones I, et al. Clinical and economic impact of implementing OVIVA criteria on patients with bone and joint infections in OPAT. Clin Infect Dis. 2019. https://doi.org/10.1093/cid/ ciz991 (epub ahead of print).

20. Mullins C, Yang K, Onukwugha E, et al. Rehospitalizations and direct medical costs for cSSSI: linezolid versus vancomycin. Am J Pharm Benefits. 2013;5:258-67.

21. Quan H, Li B, Couris CM, et al. Updating and validating the Charlson comorbidity index and score for risk adjustment in hospital discharge abstracts using data from 6 countries. Am J Epidemiol. 2011;173(6):676-82.

22. De Anda C, Anuskiewicz S, Prokocimer P, Vazquez J. Outpatient treatment of acute bacterial skin and skin structure infections (ABSSSI) with tedizolid phosphate and linezolid in patients in the United States: subgroup analysis of 2 randomized phase 3 trials. Medicine (Baltimore). 2017;96(52):e9163.

23. Shlyapnikov S, Jauregui A, Khachatryan NN, et al. Real-life evidence for tedizolid phosphate in the treatment of cellulitis and wound infections: a case series. Infect Dis Ther. 2018;7(3):387-99.

24. McKinnon P, Carter C, Girase P, Liu L, Carmeli Y. The economic effect of oral linezolid versus intravenous vancomycin in the outpatient setting: the payer perspective. Manag Care Interface. 2007;20(1):23-34.

25. Jencks SF, Williams MV, Coleman EA. Rehospitalizations among patients in the Medicare fee-for-service program. N Engl J Med. 2009;360(14):1418-28. 